\title{
Educação e arte dez anos de trajetória do GT24
}

Marcos Villela Pereira' (D)

\section{RESUMO}

O trabalho apresenta um panorama do Grupo de Trabalho Educação e Arte da ANPEd, a partir do recorte das suas matrizes de referência. Detive meu olhar sobre os objetos ou as temáticas a que se vinculam os trabalhos e as referências utilizadas. Tomado o conjunto de trabalhos apresentados entre 2007 e 2017, da 30a à $38^{a}$ Reunião, visei à identificação dos objetos, das linguagens e das áreas temáticas. Após, inventariei as referências lançadas nos 165 trabalhos, resultando em 3.225 entradas. Por fim, tomando as entradas de autores do campo da educação e arte, busquei identificar as obras mais lançadas. Os achados podem ser tomados como rastros ou indícios das escolhas teóricas realizadas nesse GT. A intenção é conhecer quais as ferramentas teóricas que o GT vem construindo e utilizando nesses dez anos para exercer a crítica, fomentar a criação de conceitos e analisar experiências no campo da educação e arte.

PALAVRAS-CHAVE

educação e arte; GT24; educação estética; resistência; crítica.

'Pontifícia Universidade Católica do Rio Grande do Sul, Porto Alegre, RS, Brasil. 


\title{
EDUCATION AND ART: TEN YEARS OF GT24'S TRAJECTORY
}

\begin{abstract}
The paper presents an overview of the Education and Art Working Group of ANPEd, based on the clipping of its reference matrices. The objects or themes to which the works are linked were its objective, as well as the references used. Considering the papers presented between 2007 and 2017, from the $30^{\text {th }}$ to the $38^{\text {th }}$ Meeting, the aim was to identify the objects, languages, and thematic areas. Afterwards, the references released in 165 works were inventoried, resulting in 3,225 entries. Finally, taking the entries of authors from the field of Education and Art, the most published papers were identified. The findings can be taken as traces or indications of the theoretical choices made in this WG. The intention is to know which theoretical tools the WG has been building and using over these 10 years to exercise criticism, to foster the creation of concepts, and to analyze experiences in the field of education and art.
\end{abstract}

KEYWORDS

education and art; GT24; aesthetic education; resistance; criticism.

\section{EDUCACIÓN Y ARTE: DIEZ AÑOS DE TRAYECTORIA DEL GT24}

\section{RESUMEN}

El documento presenta una visión general del Grupo de Trabajo de Educación y Arte de ANPEd, basado en el recorte de sus matrices de referencia. Miré los objetos o temas a los que están vinculadas las obras, así como las referencias utilizadas. Tomando el conjunto de trabajos presentados entre 2007 y 2017, de la 30 a la 38 Reunión, intenté identificar los objetos, los lenguajes y las áreas temáticas. Luego, hice un inventario de las referencias publicadas en 165 obras, lo que resultó en 3.225 entradas. Finalmente, tomando las entradas de autores del campo de la educación y el arte, busqué identificar las obras más lanzadas. Los hallazgos pueden tomarse como rastros o indicaciones de las elecciones teóricas hechas en este GT. La intención es saber qué herramientas teóricas han estado construyendo y utilizando el GT en estos 10 años para ejercer críticas, fomentar la creación de conceptos y analizar experiencias en el campo de la educación y el arte.

PALABRAS CLAVE

educación y arte; GT24; educación estética; resistencia; critica. 


\section{INTRODUÇÃO}

Este trabalho procura apresentar um breve panorama do Grupo de Trabalho Educação e Arte, o GT24 da ANPEd, a partir de alguns recortes que considero significativos para $\operatorname{tal}^{1}$. Que o leitor não espere encontrar um estado do conhecimento do GT ou uma varredura minuciosa como a que foi realizada, em 2011, pela pesquisadora Célia Maria de Castro Almeida, por ocasião do Trabalho Encomendado para a 34a Reunião Anual (Almeida, 2011). Trata-se de um ensaio analítico que pretende identificar as modas ${ }^{2}$ presentes na constituição das ferramentas teóricas utilizadas e produzidas pelo referido grupo, ao longo de dez anos, no exercício da crítica e na análise de processos pedagógicos e conceituais em adjacência ao campo da educação e arte.

Tomarei alguns aspectos de conteúdo, com vistas a desenhar uma paisagem que se constitui a partir desse olhar que lanço sobre a trajetória e sobre o presente do GT. Não vou esquadrinhar aspectos como a regionalidade dos participantes ou a origem institucional dos trabalhos, não vou olhar para as fontes de financiamento das pesquisas, não vou olhar para a natureza do vínculo ou a origem institucional dos participantes, não vou olhar para as metodologias de pesquisa praticadas nas investigações. Pretendo, tão somente, deter meu olhar em dois aspectos: os objetos ou as temáticas a que se vinculam os trabalhos e as referências utilizadas. Ainda assim, porque me interessa produzir uma leitura ampla sobre uma realidade que não cessa de se mover, não farei um esquadrinhamento de cada trabalho ou de cada reunião, mas uma leitura de sobrevoo que me permita, sem perder o rigor, esboçar um panorama muito particular.

Minha análise - e meus posicionamentos — derivam da estreita história que tenho construído no campo da arte-educação brasileira, desde meados dos anos 1980, quando era docente em um curso de licenciatura plena em Educação Artística, em uma universidade do Sul do Brasil, bem como da minha inserção na Associação Gaúcha de Arteducação (AGA) e na Federação de Arte-Educadores do Brasil (FAEB), nas quais pude integrar a equipe diretiva por diversas vezes. Para além disso, sou associado e frequento as reuniões da ANPEd desde essa época, tendo participado ativamente do movimento de criação e consolidação do GT que ora analiso.

\section{UM POUCO DA HISTÓRIA DO GRUPO DE TRABALHO}

Recuperando a narrativa feita pela pesquisadora Luciana Grupelli Loponte (2007), reporto-me ao ano de 2005, quando um grupo de pesquisadores presentes na

1 Este trabalho contou com a valiosa contribuição de Luiza de Souza Câmara, bolsista de Iniciação Científica que me acompanha desde 2018 na pesquisa "Estética da Professoralidade”, financiada pelo CNPq, no âmbito do Programa de Pós-Graduação em Educação da PUC-RS.

2 Em estatística (Bunchaft; Kellner, 1997), a moda amostral de um conjunto de dados trata do valor que ocorre com maior frequência, ou o valor mais comum, em um conjunto de dados. 
28 Reunião Anual da ANPEd, interessados em pesquisas que, de alguma maneira, estabeleciam conexões dos programas de pós-graduação em educação (PPGEs), pela operação de suas linhas e grupos de pesquisa, com o campo da arte, vindos de diferentes GTs, reuniram-se para discutir a possibilidade de criar um grupo específico para essa área temática. Loponte destaca que esse desejo "vinha sendo acalentado de forma assistemática" há alguns anos (Loponte, 2007, p. 1). Sobre esse aspecto, vale ponderar alguns pontos.

Por um lado, a partir da primeira década do século XXI se observou o significativo crescimento do número de PPGEs no Brasil, o que representa um expressivo aumento da oferta de oportunidades de produzir-se pesquisa sobre os mais diferentes objetos - educação formal e não formal, currículo, formação, prática pedagógica, aprendizagem, políticas etc., um sem-fim de possibilidades de tomar-se em análise particularidades da realidade educacional. No caso da educação, como se pode observar no Gráfico 1, "da avaliação trienal 2004-2006 para a presente avaliação [2007-2010], a área teve um crescimento de 40\% com a elevação do número de programas avaliados de 78 para 95” (Brasil, 2010, p. 2).

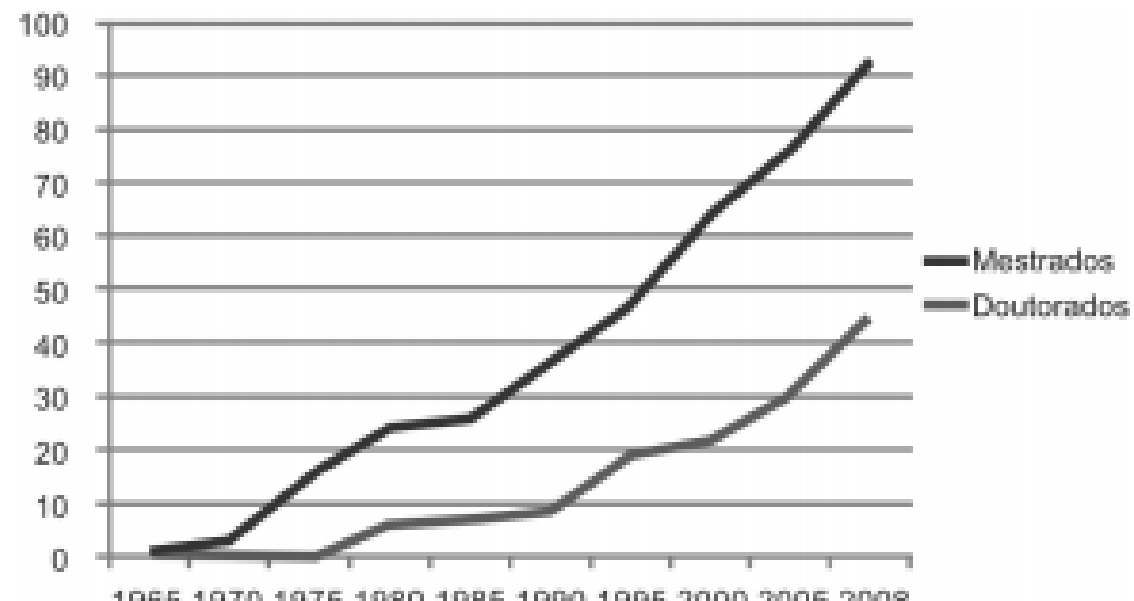

Fonte: Macedo e Sousa (2010, p. 168)

Gráfico 1 - Crescimento da Área Educação.

Essa conjuntura favorece o aumento do número ativo de pesquisadores que colocam em análise diferentes dimensões desse par articulado que é Educação e Arte no interior dos PPGEs.

Outro fator a ser destacado é a consolidação de entidades como a FAEB, a Associação Nacional de Pesquisadores em Artes Plásticas (ANPAP), a Associação Brasileira de Educação Musical (ABEM) e a Associação Brasileira de Pesquisa e Pós-Graduação em Artes Cênicas (ABRACE), entre outras, que se estabeleceram definitivamente como fori privilegiados de debate acerca das linguagens como campo epistemológico singular, explorando abordagens, metodologias, objetos e 
estratégias de formação, constituindo-se como campos consistentes e legítimos para pensar-se, ao lado da pesquisa em música ou teatro ou dança ou artes visuais, a pesquisa sobre a aprendizagem e o ensino de cada linguagem, a problematização das práticas artísticas na educação e na escola, e vice-versa. Ao lado desse aspecto, também quero mencionar as conquistas nas políticas públicas - diretrizes para a formação de professores, debates sobre a questão curricular, a consolidação das licenciaturas específicas, a delimitação das áreas de concurso público nos municípios e estados, dentre tantas outras.

Por fim, um outro ponto a ser destacado é a crescente disseminação (em especial, no Brasil) das ideias de autores alinhados às correntes comumente designadas como pós-estruturalistas, filosofias da diferença, pós-modernas. A partir da iniciativa editorial praticada por editoras como a Editora 34, que, nos anos 1990, publica um grande conjunto de obras de autores desse grupo (Deleuze, Guattari, Negri, Latour, entre outros), e da entrada dessas mesmas ideias no campo da educação, especialmente nos estudos sobre currículo (na esteira aberta pela Nova Sociologia da Educação - com a recepção de autores como Apple, Enguita, Young, Willis) - também são acolhidos os estudos foucaultianos - Rose, Gore, Hunter, Walkerdine, Varela, Larrosa, entre outros. De modo geral, pode-se observar um movimento de deslizamento das fronteiras entre os campos e, de forma exemplar, presencia-se, na primeira década do século XXI, um expressivo incremento dos estudos e das pesquisas que operam buscando abrir espaço para singularidades ainda inéditas até então.

Me permito mais uma especulação: nessa época, ainda são poucos os programas de pós-graduação da área de arte, e ainda é pequeno o espaço por eles reservado para as pesquisas que articulam educação e arte - "em 2009 a área tem 37 programas recomendados" (Brasil, 2009, p. 1) (contra 22 programas em 2003). Da mesma forma, ainda é pequena a abertura de outras áreas (como a sociologia, a antropologia ou a filosofia) para pesquisas dessa natureza. A educação, entretanto, em franca expansão, permite acolher de forma bem mais generosa essas iniciativas, proporcionando condições de possibilidade para a emergência de grupos de pesquisa e, depois, de linhas de pesquisa que tematizam ou dialogam com a arte.

Um reflexo disso é o número de trabalhos que problematizam alguma dimensão do par educação e arte, apresentados nos diferentes GTs da ANPEd ao longo dos anos (Loponte, 2007). Uma vez por ano alguns encontros se repetiam, nos corredores da reunião, em alguma mesa de trabalho ou nos intervalos: rostos conhecidos e reconhecidos experimentavam fugazes, porém intensos contatos que, com o passar do tempo e pela repetição, foram dando consistência à ideia de propormos um grupo específico.

Em 2005, portanto, foi constituída a comissão que, em 2006, submeteu à assembleia geral a proposta de criação de um GT em educação e arte. Um tema bastante problematizado foi o sentido da criação de um espaço específico: por um lado, a dispersão dos trabalhos de educação e arte nos diversos GTs já existentes podia representar uma estratégia de infiltração e de contágio dos outros campos; por outro, a criação do GT poderia contribuir para a consolidação do campo no universo da educação, resguardadas sua especificidade e sua particularidade. 
Em 2006, na assembleia geral, o embate foi bastante pautado por essa discussão. Sob certo aspecto, a diretoria questionava o expediente geral de criação de novos GTs: se formos criar um GT para cada componente curricular, a ANPEd se tornará um campo pulverizado e pautado pelos conteúdos. Nosso argumento foi em outra direção: defendeu-se a singularidade do campo da educação e arte, seu estatuto epistemológico e sua potência como área de conhecimento que poderia abarcar um grande conjunto de temas e objetos que começavam a despontar com intensidade no cenário da pós-graduação em educação (Loponte, 2007; Almeida, 2011). No ano seguinte, com status de grupo de estudo [GE] (é critério, para a ANPEd, que um grupo exista como GE por duas reuniões, antes de admitir-se seu estabelecimento como GT), tivemos 28 trabalhos aprovados (14 apresentados e 14 excedentes, todos publicados), revelando o enorme potencial que se encontrava represado até então.

O GT Educação e Arte, então, teve sua criação aprovada em 2008, na assembleia geral da $31^{\text {a }}$ Reunião Anual da ANPEd.

\section{SOBRE AS ESCOLHAS FEITAS NA SELEÇÃO E TRATAMENTO DAS INFORMAÇÕES: ALGUNS DADOS DO GRUPO DE TRABALHO}

Considerando-se o levantamento realizado por Célia Almeida (2011), a paisagem que encontro não difere muito. Varia em termos quantitativos, mas, do ponto de vista do conteúdo, ainda permanecem algumas regularidades. Vamos a elas então.

Parto do princípio de que todo trabalho de produção e tratamento de dados resulta de um impulso arbitrário de quem o faz. E de que toda objetividade não é mais do que um expediente subjetivo, uma construção racional (em que pesem as diversas formas da racionalidade) feita por um sujeito que se situa e se posiciona. Assim, o material que vou apresentar resulta de algumas escolhas e, portanto, está impregnado da minha subjetividade - ou seja, longe de pretender uma verdade sobre o GT, ofereço um instantâneo produzido a partir de um ponto de vista que é o meu, neste momento. Enquanto o fazia, sempre me questionei sobre as inúmeras possibilidades a que renunciei, buscando verificar a consistência ou a plausibilidade da minha convicção. Nesse exercício, ao mesmo tempo em que produzi dados, também produzi uma posição.

No começo, lancei-me sobre o conjunto de trabalhos apresentados nas nove reuniões em que o grupo existe como GE e como GT (sem considerar a 39a Reunião, cujos trabalhos ainda não estavam disponíveis na íntegra), com o olhar mais desinteressado, a atenção flutuante característica de um estudo exploratório em seus primeiros movimentos. $\mathrm{Na}$ medida em que fui avançando no trabalho de manejo do material, alguns recortes foram sendo escolhidos - em favor de infinitos outros, que não foram feitos, mas permanecem possíveis. O conjunto de trabalhos é público e está acessível por meio da página da ANPEd³: clicando-se em cada reunião, abre-se uma nova página, na qual podem ser localizados o GT e seus trabalhos daquela edição.

3 Disponível em: http://anped.org.br/reunioes-cientificas/nacional. Acesso em: 12 jul. 2019. 
O primeiro movimento foi mapear os trabalhos aprovados em cada reunião. Optei por não separar os trabalhos apresentados dos trabalhos excedentes porque quis considerar o conjunto de trabalhos efetivamente aprovados pelo Comitê Científico (avaliação feita, em primeira instância, por avaliadores ad hoc do próprio GT e membros da subárea no comitê, e, em segunda instância, pelos representantes do GT no comitê, podendo haver interposição e julgamento de recursos como instância final). Pelo mesmo motivo, optei por não considerar os trabalhos encomendados, uma vez que não são submetidos a esse processo de avaliação. Ao fazer essa escolha, estou privilegiando olhar as escolhas que o próprio GT faz, para se constituir como um coletivo acadêmico: a seleção dos trabalhos é feita, em última análise, por um grupo de sujeitos oriundos do próprio GT. Ao fazer esse recorte, considero que o panorama encontrado não é fortuito (uma amostra geral, neutra, do estado do tema da educação e arte na pós-graduação em educação brasileira), mas resultado de um arbitrário que se pauta em critérios definidos e praticados por sujeitos que se posicionam dentro de um campo de conhecimento e, a partir dessa posição de sujeitos de saber, exercitam seu poder de decisão ao aprovar ou reprovar um trabalho - com base em critérios objetivos, definidos, de forma geral, pelo Comitê Científico em seus documentos orientadores para a avaliação, mas, igualmente, com base em critérios coletivos (produto de acordos tácitos estabelecidos no âmbito do GT) e individuais (que considera a premissa da autonomia e independência do avaliador, no momento da avaliação).

Ou seja, o corpus considerado neste trabalho deriva de uma ação arbitrária racionalmente fundamentada e tem por efeito a constituição do GT como um espaço que favorece a circulação de ideias e posições que, de maneira geral, correspondem às ideias hegemonicamente estabelecidas em sua constituição - coordenação e vice-coordenação, titular e suplentes no Comitê Científico, bem como avaliadores ad hoc escolhidos no GT. O que estou sugerindo é que o GT, utilizando os expedientes de gestão que lhe são legitimamente conferidos por sua condição estatutária e regimental, e utilizando uma prerrogativa que lhe é singular, constitui-se como uma formação social que opera certo discurso, coloca em ação certos modos de prática e promove certos modos de coexistir e conviver, ou seja, é responsável pela sua própria constituição como um coletivo que discute, de uma forma muito particular, certo modo de considerar a interimplicação entre educação e arte no âmbito dos PPGEs brasileiros. Qualquer generalização terá como ponto de partida a iniciativa de considerar-se como universal uma ideia ou uma representação que, tendo origem em uma particularidade, ascendeu momentaneamente a uma posição hegemônica e, dessa forma, se apresenta como um arbitrário que, naquela circunstância ou contexto, pretende-se uma generalização.

Em síntese: o que quero dizer é que o panorama que ofereço resulta de uma leitura que faço do movimento do próprio GT. Não se trata de um panorama ou do estado do conhecimento sobre educação e arte, mas do resultado da ação sistemática e continuada de um coletivo que, ao se constituir, demarca sua própria constituição. A sucessiva circulação de membros pelas diferentes posições vai dando ao GT uma face diferente, em cada reunião. Tomando-se o intervalo analisado, não se trata de configurar uma síntese definitiva ou uma identidade, mas de produzir um instantâneo, um olhar sobre esse conjunto que não cessa de se movimentar, cada vez que cada um coloca seus olhos sobre ele. 
Talvez pudesse tomar cada reunião, em particular, e analisar cada processo mapear os trabalhos submetidos, identificar os avaliadores et cetera, mas isso já seria um exercício impróprio, como se de busca por responsáveis ou culpados, como se isso pudesse nos conduzir a uma espécie de verdade última de cada reunião, cuja soma resultasse na verdade última do GT. Ora, além de impróprio, seria inadequado alimentar semelhante pretensão: não há uma verdade última que se possa encontrar. Parafraseando Nietzsche, diria que não há verdades, somente perspectivas e interpretações.

Assim, portanto, dando início ao mapeamento, considerando-se o intervalo entre a $30^{\mathrm{a}}$ e a $38^{\mathrm{a}}$ reuniões, inclusive, chegou-se ao total de 165 trabalhos aprovados em 9 reuniões, assim distribuídos, como exposto no Quadro 1.

Quadro 1-Trabalhos aprovados por reunião.

\begin{tabular}{|l|c|c|}
\hline Reunião & Ano & Número de trabalhos \\
\hline $30^{\mathrm{a}}$ & 2007 & 28 \\
\hline $31^{\mathrm{a}}$ & 2008 & 19 \\
\hline $32^{\mathrm{a}}$ & 2009 & 15 \\
\hline $33^{\mathrm{a}}$ & 2010 & 14 \\
\hline $34^{\mathrm{a}}$ & 2011 & 16 \\
\hline $35^{\mathrm{a}}$ & 2012 & 14 \\
\hline $36^{\mathrm{a}}$ & 2013 & 17 \\
\hline $37^{\mathrm{a}}$ & 2015 & 22 \\
\hline $38^{\mathrm{a}}$ & 2017 & 20 \\
\hline Total & & 165 \\
\hline
\end{tabular}

Pode-se observar que, até a $36^{\text {a }}$ Reunião, a frequência era anual, passando a bianual a partir da 37a. Isso alterou o formato da rotina dos GTs, possibilitando que se aprovasse um número maior de trabalhos para serem apresentados em cada reunião (antes limitado para até 12 trabalhos, passando para até 24 trabalhos, quando não há trabalho encomendado - no caso de haver, o limite é reduzido). Também é importante registrar a mudança de política orientadora para a aprovação de trabalhos excedentes (aprovados, mas sem lugar na grade de apresentação): a orientação da diretoria foi no sentido de limitar-se esse número drasticamente - esse tema foi amplamente debatido no âmbito do Comitê Científico, considerando-se injustificável a arbitrariedade no estabelecimento do número máximo de trabalhos a serem aprovados como excedentes, para além daqueles que seriam apresentados. De todo modo, pode-se observar que a curva é descendente até 2010, para, lentamente, retomar a subida.

Eventualmente, poder-se-ia analisar o número de trabalhos submetidos, como fez Almeida (2011), mas, para o escopo desta mirada, esse não era um fator significativo. De qualquer modo, essa informação pode ser obtida nos Relatórios do GT ${ }^{4}$.

4 Disponíveis em: http://anped.org.br/documentos/relatorios. Acesso em: 12 jul. 2019. 
O segundo movimento realizado visou à identificação dos objetos, das linguagens ou das áreas temáticas dos trabalhos. $\mathrm{Na}$ mesma direção seguida pelo trabalho de Almeida (2011), debrucei-me sobre os títulos, das palavras-chave e dos resumos, buscando identificar o traço predominante em cada trabalho. Muitos deles permitiam seu enquadre em mais de uma categoria (formação de professores e artes visuais, por exemplo). Nesses casos, detive-me no resumo, buscando identificar qual era o aspecto mais prevalente, de modo a classificar o trabalho em apenas uma categoria. Cada pesquisador poderá aplicar diferentes critérios para esse exercício e chegar a diferentes classificações. Como já afirmei, não é minha pretensão encontrar "a verdade do GT24", mas desenhar uma paisagem a partir de um exercício analítico. Enfim, chegou-se à distribuição exposta no Quadro 2.

Quadro 2-Distribuição de trabalhos por tema.

\begin{tabular}{|l|c|}
\hline Temática & Número de trabalhos \\
\hline Artes visuais & 36 \\
\hline Teatro, dança, corpo, performance & 32 \\
\hline Estética, cultura e teorias da arte & 29 \\
\hline Formação de professores & 27 \\
\hline Escola, ensino, aprendizagem & 21 \\
\hline Música & 16 \\
\hline Museu & 4 \\
\hline Total & 165 \\
\hline
\end{tabular}

$\mathrm{Na}$ temática das artes visuais, encontram-se trabalhos que colocam em pauta o cinema, a fotografia, a arquitetura e o urbanismo, a cultura visual, o desenho, os ateliês et cetera. Esse já era o maior grupo em 2011, quando da pesquisa de Almeida (2011), e denota um pouco a hegemonia das artes visuais, em suas diferentes formas de ocorrência, no campo da educação.

O segundo grupo foi difícil de constituir. Em que pese a presença de trabalhos bem específicos no teatro e na dança, alguns tomam em questão as duas linguagens, dificultando a categorização. Igualmente, há os que tematizam o corpo e a performance explorando-os como objetos localizados em uma zona de fronteira entre aquelas duas linguagens, também dificultando a separação. Optei por agrupar o conjunto todo, em que pese o reconhecimento de que são linguagens diferentes, do ponto de vista epistemológico e estético.

O terceiro conjunto agrupa os trabalhos de cunho mais ensaístico e/ou analítico, em adjacência com o campo de estudos filosóficos, literários, sociológicos ou antropológicos. Estética, experiência estética, literatura, poesia e cultura são alguns dos temas que aparecem com frequência nesse grupo.

O quarto e quinto conjuntos também são difíceis de demarcar: uma vez que todos os trabalhos versam sobre educação e arte, todos poderiam estar em um 
desses dois grupos. Como já mencionei, deliberei agrupar, no primeiro, aqueles que declaradamente colocaram em análise aspectos da formação (currículo, diretrizes, estágios etc.), mesmo quando dirigidos para uma linguagem em particular. No segundo, agrupei aqueles que, independentemente da linguagem em questão, pautaram aspectos da prática pedagógica (predominantemente escolar, mas também não escolar), questões relativas à aprendizagem ou ao ensino, à análise de livros didáticos, aos relatos de experiências de trabalho, entre outras. Se tomados em conjunto, esses dois grupos perfariam 48 trabalhos - quase um terço do conjunto todo: esse dado (que poderia representar a moda, no nosso caso) pode sugerir um traço de pertinência e consistência da temática principal do GT, podendo operar como evidência de sua consolidação no âmbito da pesquisa e da pós-graduação em educação, aqui tornadas visíveis nas reuniões nacionais ANPEd.

O sexto grupo traz os trabalhos que, de forma explícita, colocam em análise a música e a educação musical. Um aspecto importante a ser mencionado é o fato de que, por muito tempo, a reunião nacional da ANPEd aconteceu no mesmo período em que a reunião da $\mathrm{ABEM}$ - fato que justifica o baixo número de trabalhos dessa área no nosso $\mathrm{GT}^{5}$.

Por fim, o último grupo agrega trabalhos que pautam a realidade ou a experiência com museus. Optei por manter esses trabalhos nessa categoria porque considerei que há algo de singular nessa realidade de trabalho que os distingue das outras formas de educação. Talvez pudéssemos ter uma categoria que ponderasse a educação não escolar, acrescentando-se o cinema, a galeria, a rua, o teatro et cetera. Mas isso já seria outro trabalho.

Também decidi considerar o conjunto dos 165 trabalhos sem experimentar essa categorização em cada uma das reuniões, em separado. O motivo é o mesmo já mencionado: o objetivo deste trabalho é produzir um panorama do GT, como um todo, nesses dez anos de existência.

Um aspecto importante a ser considerado diz respeito à nossa tendência de converter qualquer classificação em um ranking. Não há dúvida de que nosso olhar analítico sempre vai produzir um julgamento de valor e atribuir, portanto, um sentido hierárquico à classificação como um todo ou aos elementos no interior de cada estrato. Esta mirada que apresento, ainda que o faça dando ênfase à posição quantitativa, não tem o propósito de sugerir que aquelas categorias com mais elevada expressão numérica estejam em posição superior em relação às outras. Poderia ter optado por apresentar o quadro em ordem alfabética ou outro critério: o valor numérico indica frequência, mas a frequência não implica, por si só, um atributo positivo ou negativo.

5 De 2005 a 2010, os congressos da ABEM e as reuniões da ANPEd aconteceram praticamente nas mesmas datas, com algumas pequenas variações de dias, em alguns casos. A partir de 2011, os congressos da ABEM passaram a ser bianuais, o que somente aconteceu a partir de 2013, no caso da ANPEd - em 2012, portanto, houve reunião da ANPEd, mas não houve congresso da ABEM. Em 2015, os eventos já se realizaram em meses diferentes (um em outubro e o outro em novembro, com três dias de intervalo entre eles). 
Quando menciono a posição hegemônica das artes visuais no âmbito da educação (escolar, em especial), o faço levando em consideração a tradição brasileira e a assimetria no número de cursos de licenciaturas nas diferentes linguagens: atualmente, temos 121 cursos de formação de professores em artes visuais, dentro de um total de 368 cursos de formação de professores em artes — considerando-se artes, artes visuais, dança, música, teatro e cinema e audiovisual (Brasil, 2019). Quando sinalizo para o número de trabalhos de música e observo a coincidência com as reuniões da ABEM, estou reafirmando que meu olhar, a despeito de estar dirigido para o interior do GT, não deixa de contemplar para outros espaços, eventos e circunstâncias. Da mesma maneira, quando destaco que 48 trabalhos colocam em pauta a formação e a prática pedagógica, não quero fazer crer que isso é melhor ou pior, mas que evidencia a tendência de o GT Educação e Arte constituir-se como um campo particular no interior do campo geral que é a educação - aliás, como também já mencionei, seria plausível afirmar que os 165 trabalhos tematizam a relação entre educação e arte, o que tornaria sem efeito qualquer outra classificação. Enfim, torno a destacar o fato de que essa classificação é arbitrária e responde a critérios que eu defini como razoáveis para o tipo de leitura que, nesta circunstância, me convém.

\section{EDUCAÇÃO, ARTE E RESISTÊNCIA: A QUE RESISTIMOS E COMO RESISTIMOS}

A ciência, ancorada nos expedientes formais da classificação, ordenação e seriação, nasce como abertura ao duvidoso, ao incerto, ao desconhecido, mas logo coloca em operação sua força mais vigorosa: a de resolver a dúvida, de converter a incerteza em certeza, de conhecer o desconhecido e, assim, neutraliza o devir (Barcellona, 1996). Este trabalho não deixa de ser, como os demais, um exercício orientado pelo princípio científico e, em que pesem todos os questionamentos que fazemos sobre a ciência, ainda é a ela que nos rendemos nos embates por posições mais ou menos privilegiadas no campo acadêmico.

A arte é, notadamente, um privilegiado veículo de resistência à hegemonia dessa forma de racionalidade que contaminou o mundo a partir da modernidade. Se a ciência se apoia na tensão entre certeza e incerteza, a arte possibilita o deslizar em um universo em que não há pontos de ancoragem senão momentâneos, precários, provisórios e parciais. A arte leva a possibilidade sempre ao seu próprio limiar e, em vez de estacionar, como diante do limite, lança-se e lança o sujeito na direção do inédito, do ainda-não.

Se estamos operando no âmbito da pesquisa e da pós-graduação, estamos reféns de alguns critérios de rigor que, hegemonicamente, ainda remetem ao estatuto da ciência. O campo acadêmico se constitui sob esse estatuto, inegavelmente. E nossa tarefa tem sido furar o bloqueio, resistir, experimentar outras alternativas, deslizar pelas frestas, escapar pelas brechas, sempre pagando o preço do paradoxo: como escapar do sistema sem sair do sistema? Em outro momento (Pereira, 2012), já especulei um bocado acerca da experiência estética como estratégia de subjetivação, e já defendi o sentido da experiência como uma jornada do sujeito na direção do ainda-não-sido. 
Quando pensamos a constituição do GT Educação e Arte, dentre outras atitudes, postulamos sua existência como consolidação de uma iniciativa e demarcação de um indício da possibilidade da resistência, da (auto)criação e da disrupção no interior do campo da educação. Esse campo, definido, muitas vezes, como constituído pelas chamadas ciências da educação, em adjacência à pedagogia e em relação estreita com a forma escolar, em muito se caracteriza como a mais importante máquina civilizatória operada a partir da modernidade - o modelo daquilo que se chama "educacional" se baseia na modificação do modo de pensar do outro como efeito da ação educativa que se exerce sobre ele. Seja qual for o mote (a depender de quem julga, considera-se que é "para o bem" ou "para o mal"), a ação educativa sempre implica em uma ação sobre um sujeito, individual ou coletivo, com o intuito de fazer com que ele deixe de pensar como vinha pensando e passe a pensar, sobre as mesmas coisas, de forma diferente. O propósito do esclarecimento é este: fazer com que o homem saia do estado de menoridade em que se encontra (Kant, 1985) - só que Kant não define nem sugere em que direção: trata-se de "sair" da menoridade, e não de "chegar" a algum lugar. Continuamos com o paradoxo: a mesma razão que nos submete e assujeita é a razão com que teremos de lidar para escapar dela. Já aprendemos com Foucault, por exemplo, que a experiência é arriscar a não ser mais o que se tem sido (Foucault, 2018, p. 29). E não é à toa que a arte se converte em paradigma para a experiência: é quase possível identificar a arte e a experiência estética — só não acontece quando uma das duas é capturada pelo estatuto da ciência e perde a potência da abertura dada pela possibilidade da invenção e se submete às condições de controle, explicação e esforço de previsibilidade comumente praticadas por esta.

Quando constituímos um GT sob a temática da educação e arte, no âmbito da Associação Nacional de Pós-Graduação e Pesquisa em Educação, é inegável que o fazemos, sob o signo desse mesmo paradoxo: por um lado, reiteramos a constituição desse campo sob o domínio do campo mais amplo da educação - das ciências da educação - e, dessa maneira, nossa constituição se dá condicionada pelo estatuto da ciência; por outro lado, nossa pretensão é nos infiltrarmos no interior desse campo com o propósito de miná-lo e fazer proliferar as brechas que, de alguma maneira, poderiam tornar possível a subversão daquele expediente civilizatório que é a forma escolar. Sob certo aspecto, é como se tivéssemos consentido em ser assujeitados no interior do campo das ciências da educação para, em um estratégico movimento de virada, exercer a prerrogativa da crítica e, desde o interior mesmo desse campo, exercer práticas de resistência que possibilitassem minar a educação assujeitadora com intenções e ideias emancipatórias. Como o próprio trabalho com arte no cotidiano da escola: ainda que curricularizado, submetido à regulação estrutural da forma escolar, sob todas as linhas de controle como o tempo e o espaço da aula, a arte consegue, às vezes, produzir movimentos de resistência que permitem romper aquela matriz reprodutivista e conservadora, que subjetiva os sujeitos pelo assujeitamento incondicional e promove exercícios de criação e experiências singulares.

Se a educação também pode ser um vetor de emancipação, contribuindo para a tomada de consciência, pelo sujeito, das armadilhas em que foi capturado sistematicamente ao longo de seu processo de formação, é porque ela lança mão do mesmo dispositivo disparador que a arte: a crítica. Foucault, recorrendo a Bataille, afirma que a experiência 
não é a afirmação do sujeito na continuidade fundadora de seu projeto. É antes nessa ruptura e nesse risco pelo qual o sujeito aceita sua própria transmutação, transformação, abolição, em sua relação com as coisas, com os outros, com a verdade, com a morte, etc. É isso, a experiência, é arriscar não ser mais si-mesmo. (Foucault, 2018, p. 29)

Para ele, "a crítica teria essencialmente por função o desassujeitamento no jogo do que poderia se chamar, em uma palavra, a política da verdade" (Foucault, 2005, p. 78). Trata-se da prerrogativa que o sujeito tem de, em um lance estratégico, escapar ao assujeitamento a que está vinculado, ainda que isso signifique inaugurar outra posição igualmente sujeitada. Se a submissão a uma verdade é mais uma questão de aceitabilidade do que de legitimidade, nossa saída é ter discernimento suficiente para decidir qual a verdade que aceitaremos, e quando, e em que condições, e qual, pelo menos nesse momento, não aceitaremos.

Evidentemente, não é pretensão, aqui, apresentar a arte como redentora ou como incondicionalmente emancipatória. Por excelência, nenhuma prática humana é puramente boa ou má. É o próprio Foucault (2005) que nos ensina que não é possível não ser governado. No caso da arte (e, notadamente, da arte-educação), a história nos dá evidências. Em Dewey (1959), por exemplo, a arte era tomada como uma forma da experiência e, portanto, responsável pelo deslocamento do sujeito no sentido da ampliação dos seus horizontes. Ao longo do século XX, pudemos ver a emergência dos movimentos da "Educação através da Arte" com toda a sua ambiguidade de destacar a arte como vetor privilegiado para proporcionar a educação e a formação de um sujeito crítico ao mesmo tempo que favoreceu a submissão da arte às outras disciplinas, caracterizando-a como mais um recurso didático do que um campo epistemológico (Barbosa, 1989). É principalmente na segunda metade do século passado que o deslocamento da pergunta “o que é arte?” para "quando é arte?" aparece como atitude exemplar de um tempo que passa a compreender a experiência estética com a arte como uma experiência radical de estranhamento que proporciona condições de possibilidade de o sujeito colocar em questão as suas certezas e experimentar a plausibilidade de outros juízos ante a experiência (Goodman, 2007; Duve, 2009).

No caso de compreendermos a arte como dispositivo emancipatório, trata-se de criar verdades provisórias, inventar verdades temporárias sem parar. Quando uma dessas verdades se estabelece por mais tempo, quando ela dura um pouco mais, sem se desvanecer, ela tende a absorver o status da verdade que fica e aprisiona - da qual é necessário sempre se emancipar. A emancipação, portanto, não é um estado a que se chega, como uma condição estável e duradoura, como uma identidade: não é possível pensar-se em um sujeito ou um coletivo emancipados como se tratando de um sujeito ou um coletivo plenamente desassujeitados. A emancipação constitui o modo de vida próprio dos sujeitos e um coletivo que não cessam de colocar em questão as verdades e as convicções a que se sujeitam, sempre dispostos a renunciar à própria vida se a condição de viver for a sujeição inexorável. A emancipação é a característica das existências que colocam em prática a crítica, e por crítica entendo “a arte de não ser governado desse modo e a esse preço” (Foucault, 2005, p. 76). 


\section{A FACA DE DOIS GUMES: QUEM NOS ATACA, QUEM ESTAMOS ATACANDO}

Voltemos, então, à análise do material do GT. O movimento seguinte a que me lancei foi o de inventariar a biblioteca dos autores que tiveram seus trabalhos aprovados, ou seja, acessamos as páginas das nove reuniões (da $30^{\mathrm{a}}$ à $38^{\mathrm{a}}$ ) e delas extraímos os arquivos de cada um dos trabalhos aprovados. Após isso, fui atrás de extrair e agrupar todas as referências lançadas nos 165 trabalhos. Foi gerada, assim, uma lista com 3.225 entradas - uma média de 19 a 20 entradas por trabalho.

Por que me refiro a "entradas"? Porque não há unidade no modo como as referências são registradas e isso dificulta muitíssimo uma análise mais rigorosa. Tratei, portanto, de considerar apenas o lançamento feito pelo autor do trabalho: quando um livro tem entrada indireta (ou seja, quando a referência principal é um capítulo da obra coletiva), considerei como válida a referência ao autor do capítulo, e não ao autor do livro. Também desconsiderei as entradas relativas a documentos oficiais (leis, resoluções e similares) - apesar de considerá-las no cômputo geral (para integrar o corpus completo), não as levei em consideração quando da tabulação das frequências, uma vez que meu interesse era encontrar as matrizes de referência das quais está impregnado o nosso GT.

Por falar em frequência, novamente chamo a atenção para o fato de que as indicações de frequência acabam por gerar uma lista ordenada por quantidades. Essas frequências não querem dizer que os autores ou as obras mais citadas são melhores ou mais verdadeiros do que os outros: a frequência mais alta indica os autores e as obras mais aceitos pelo GT. Trata-se, como já mencionei, de uma questão de aceitabilidade: uma ideia é tida ou considerada verdadeira quanto mais aceitabilidade ela tiver. Não é porque tem legitimidade que uma ideia é considerada verdadeira, mas porque é aceita como tal.

E aqui está a faca de dois gumes a que fiz menção: essa ideia que neste momento empunhamos como arma ou ferramenta, na prática da ação estratégica da crítica e da emancipação, há pouco tempo era uma ideia que operava de fora para dentro de nós, buscando-nos como foco. Em algum momento, antes, não pensávamos como pensamos agora - não tínhamos lido o que viemos a ler, não sabíamos o que viemos a saber, não conhecíamos o que viemos a conhecer. Se pensamos como pensamos, agora, é porque, em algum momento, deixamos de pensar como vínhamos pensando até então, e passamos a pensar como pensamos agora: o tempo todo experimentamos a condição de poder pensar as mesmas coisas de forma diferente por efeito da atitude crítica que vimos desenvolvendo ao longo da nossa formação.

Não significa que temos de renunciar, inexoravelmente, o que pensamos - a atitude crítica nos convida e nos lança no movimento de colocar em questão as convicções que temos, levando-nos a refletir sobre as implicações que essas ideias e convicções têm tido, estão tendo e podem vir a ter no conjunto de práticas que levamos a efeito no interior das diferentes formações sociais que atravessamos a cada momento. Ou seja, a atitude crítica nos lança na direção da suspeita sobre nós mesmos. E é um pouco isso que me interessa fazer, neste momento. Vejamos. 
Mapeando o total de 3.225 entradas de referências, identifiquei os autores que tinham mais de 10 e 5 entradas (lembro-me de que, como disse acima, não considerei as entradas secundárias, somente as principais). Alguns quadros foram gerados, buscando identificar esse conjunto: em primeiro lugar, agrupei os autores que tiveram dez ou mais entradas (conforme Quadro 3) e, em outro quadro, aqueles que tiveram entre cinco e nove entradas (conforme Quadro 4). Depois, cada quadro foi dividido entre "autores de referência geral" e "autores do campo educação e arte". Nesse segundo movimento, também apareceram problemas: John Dewey, por exemplo, é um autor de referência geral ou um autor do nosso campo? Nesse caso, e em outros, similares, levei em consideração as obras referenciadas - no caso de Dewey, ele acabou ficando entre os "autores de referência geral". Outras situações foram ao contrário: Jorge Larrosa e Virgínia Kastrup, por exemplo, tomando em consideração as obras referenciadas, foram agrupados junto dos autores do nosso campo. Se tomamos o conjunto todo, encontramos 111 autores com 5 ou mais

Quadro 3-Frequência dos autores referenciados (geral).

\begin{tabular}{|c|c|}
\hline $\begin{array}{l}\text { Número de } \\
\text { entradas }\end{array}$ & Autores \\
\hline 80 & DELEUZE, Gilles \\
\hline 76 & BARBOSA Ana Mae \\
\hline 73 & FOUCAULT, Michel \\
\hline 64 & DELEUZE \& GUATTARI \\
\hline 50 & BENJAMIN, Walter \\
\hline 39 & LAROSSA, Jorge \\
\hline 36 & BACHELARD, Gaston \\
\hline 34 & FREIRE, Paulo \\
\hline 32 & NIETZSCHE, Friedrich \\
\hline 20 & VIGOTSKI, L. S. \\
\hline 19 & MAFFESOLI, Michel; DEWEY, John; BOURDIEU, Pierre \\
\hline 18 & DUARTE Jr, João Francisco; HERNANDES, Fernando \\
\hline 16 & LOPONTE, Luciana; CORAZZA, Sandra \\
\hline 15 & JUNG, Carl G.; BARTHES, Roland \\
\hline 14 & MARTINS, Mirian Celeste \\
\hline 13 & SCHECHNER, Richard; BAKHTIN, Mikhail; AGAMBEN, Giorgio \\
\hline 12 & $\begin{array}{c}\text { KOUDELA, Ingrid; PEREIRA, Marcos Villela; KASTRUP, Virgínia; KRAMER, } \\
\text { Sonia; SILVA, Tomaz Tadeu da; RANCIẼRE, Jacques; GOODSON, Ivor; } \\
\text { BERGSON, Henri }\end{array}$ \\
\hline 11 & SPOLIN, Viola; GUATTARI, Félix; CERTEAU, Michel de; BARROS, Manoel de \\
\hline 10 & $\begin{array}{l}\text { SOUZA, Jusamara; PEREIRA, Marcelo; MEIRA, Marly; EISNER, Elliot; } \\
\text { BELLOCHIO, Cláudia; HEIDEGGER, Martin; HALL, Stuart; BAUMAN, Zygmunt }\end{array}$ \\
\hline
\end{tabular}


Quadro 4-Frequência dos autores referenciados (Arte).

\begin{tabular}{|c|c|}
\hline $\begin{array}{l}\text { Número de } \\
\text { entradas }\end{array}$ & Autores \\
\hline 76 & BARBOSA Ana Mae \\
\hline 39 & LAROSSA, Jorge \\
\hline 18 & DUARTE Jr., João Francisco; HERNANDES, Fernando \\
\hline 16 & LOPONTE, Luciana; CORAZZA, Sandra \\
\hline 14 & MARTINS, Mirian Celeste \\
\hline 13 & SCHECHNER, Richard; \\
\hline 12 & KOUDELA, Ingrid; PEREIRA, Marcos Villela; KASTRUP, Virgínia; \\
\hline 11 & SPOLIN, Viola; \\
\hline 10 & $\begin{array}{l}\text { SOUZA, Jusamara; PEREIRA, Marcelo; MEIRA, Marly; EISNER, Elliot; } \\
\text { BELLOCHIO, Cláudia; }\end{array}$ \\
\hline 9 & $\begin{array}{l}\text { SCHAFER, Murray; RICHTER, Ivone; PILLAR, Analice; PENNA, Maura; } \\
\text { OSTETTO, Luciana }\end{array}$ \\
\hline 8 & $\begin{array}{l}\text { RYANGAERT, Jean-Pierre; OSTROWER Fayga; MARQUES, Isabel; } \\
\text { CANCLINI, Nestor Garcia; BASBAUM, Ricardo }\end{array}$ \\
\hline 7 & $\begin{array}{l}\text { ZUMTHOR, Paul; SWANWICK, Keith; NOGUEIRA, Monique Andries; FUCCI- } \\
\text { AMATO, Rita; FIGUEIREDO, Sérgio Luiz; EFLAND, Arthur; DIAS, Belidson }\end{array}$ \\
\hline 6 & $\begin{array}{l}\text { VILLA-LOBOS, Heitor; STRAZZACAPPA, Marcia; (SANTIAGO, R.; } \\
\text { MONTI, E.; IVENICKI, A.)7; SANTAELLA, Lúcia; LEITE, Maria Isabel; } \\
\text { LAZZARIN, Luís Fernando; ICLE, Gilberto; FISCHER, Rosa Maria B; DIDI- } \\
\text { HUBERMAN, Georges; DESGRANGES, Flávio; AZEVEDO, Fernando }\end{array}$ \\
\hline 5 & $\begin{array}{l}\text { RICHTER, Sandra; MARTINS, Raimundo; LABAN, Rudolf; JOBIM E SOUZA, } \\
\text { Solange; HERMANN, Nadja; GUMBRECHT, Hans Ulrich; FUKS, Rosa; FRANGE, } \\
\text { Lucimar Bello; COSTA, Marisa Vorraber; CLARK, Lygia; CANTON, Kátia }\end{array}$ \\
\hline
\end{tabular}

Este conjunto de autores aparece referenciado seis vezes em um único trabalho. Trata-se de seis artigos ou trabalhos escritos pelos três autores, em conjunto, referenciados em um único trabalho e, por isso, a frequência elevada teve destaque. Nesse caso, para cômputo numérico, foram considerados como uma única entrada, como se fosse um autor apenas.

entradas. Destes, 55 pertencem ao grupo de "autores de referência geral" e 56 pertencem ao grupo de "autores do campo da educação e arte" (estes últimos aparecem no Quadro 4), mostrando significativo equilíbrio.

Da mesma forma que sugeri na análise feita sobre as temáticas dos trabalhos, cheguei a pensar em mapear as reuniões em separado, mas renunciei essa ideia por considerar que ela até poderia esclarecer algumas ocorrências (do tipo um autor que fez referência a um elevado número de obras de um mesmo autor, fazendo aumentar sua frequência, mesmo que esse mesmo autor ou obras não tenham sido lançados em nenhum outro trabalho), mas também poderia gerar distorções por tomar particularidades demasiadamente estreitas.

Comecemos pelo quadro geral, que apresenta a frequência de autores com mais de dez entradas, sem discriminar autores de referência geral e autores de referência do campo (Quadro 3). 
Observa-se que o autor com mais entradas, no conjunto geral, é Gilles Deleuze (com 80 entradas). Se considerarmos as entradas dele e em conjunto com Guattari (DELEUZE + DELEUZE e GUATTARI ${ }^{6}$ ), chegamos ao montante de 144 entradas - o que sugere que esse é o autor com maior aceitação dentro do GT24. Logo a seguir, ainda dentre os autores de referência geral, encontramos Michel Foucault (com 73 entradas) e Walter Benjamin (com 50 entradas). Esse achado reforça, sob certo aspecto, minhas considerações acerca do potencial de crítica que atravessa nosso GT: são autores contemporâneos que capitaneiam com vigor a ideia de experiência e crítica, produzindo importantes deslocamentos nos modos habituais de se pensar as mesmas coisas.

Se a conclusão for rápida, podemos dizer que o GT24 é deleuziano, ou deleuzefoucaultiano. No entanto, mais do que buscar os autores como uma marca epistemológica ou teórica, esta análise pretende tão somente indicar que linhas e autores impregnam com mais frequência as pesquisas que foram aprovadas pelo grupo. Trata-se de identificar quais autores têm mais aceitação, nesses dez anos. Há análises mais profundas e minuciosas que poderiam ser feitas - como, por exemplo, identificar não apenas os autores mais referenciados, mas os trechos mais citados no corpo dos trabalhos. Essa, sim, seria uma maneira de mapear que ideias aparecem mais frequentemente repetidas, quais são os bordões, as palavras de ordem mais frequentes no conjunto de trabalhos.

Entretanto, não é essa a intenção. $O$ mapa de frequências apenas proporciona um panorama sobre a moda: que ideias e autores têm mais ocorrência no conjunto de trabalhos. Dentre aqueles que tiveram 10 ou mais lançamentos predominam os autores de referência geral ( 27 autores gerais ante 17 do campo - destacados no Quadro 4, abaixo). Uma inferência possível é que operamos em um universo tão diverso (o trocadilho é proposital) que, considerando-se a heterogeneidade temática, seria difícil que tivéssemos encontrado frequências mais elevadas entre os autores do campo do que entre os de referência geral — ora, é porque se trata de "referência geral" que a frequência é mais elevada.

Se considerarmos a especificidade do campo educação e arte, a autora com mais alta frequência de entradas é Ana Mae Barbosa (76 lançamentos), reiterando o que já havia sido registrado por Célia Almeida (2011): ela é a autora, no nosso campo, com maior aceitação, seguida por Jorge Larrosa (39 entradas). Igualmente, trata-se de dois autores que, cada um a seu modo, impulsionam a crítica como estratégia e a experiência como expediente de referência para a análise e a reflexão.

Se tomarmos em consideração apenas os autores do campo educação e arte, agora levando em conta aqueles que tiveram cinco ou mais entradas, chegamos ao Quadro 4.

6 Como explicado, para efeitos desta contabilização, a entrada "Deleuze e Guattari", quando se tratava de obra ou artigo conjunto, foi considerada como um autor só. Assim, temos as entradas "Deleuze", "Guattari" e "Deleuze e Guattari" como três entradas distintas. 
Eis aí o conjunto de 56 autores do campo da educação e arte que tiveram 5 ou mais entradas nas referências dos 165 trabalhos aprovados pelo GT24 entre a $30^{\mathrm{a}}$ e a $38^{\mathrm{a}}$ Reuniões da ANPEd. Trata-se dos autores que, neste momento, dentro do recorte apresentado, têm maior aceitabilidade para o grupo.

Por fim, aprofundando a análise das ocorrências, tomei as entradas de autores do campo da educação e arte, e busquei identificar as obras mais lançadas. Não me ative aos autores de referência geral, mas apenas aos de nosso campo, por considerar que essa especificidade poderia trazer alguma novidade. Ao inventariar os produtos (livros e artigos) mais citados, observei que as frequências mais altas foram as seguintes: 15 entradas do artigo "Notas sobre a experiência e o saber de experiência", de Jorge Larrosa; 10 entradas para as obras "A imagem no ensino da arte", de Ana Mae Barbosa, e "Cultura Visual: mudança educativa e projeto de trabalho", de Fernando Hernandes; e 8 entradas para "Interculturalidade e estética do cotidiano no ensino das artes visuais", de Ivone Richter, "Filosofia da criação: reflexões sobre o sentido do sensível", de Marly Meira, e "Tópicos Utópicos" e "Inquietações e mudanças no ensino da arte", ambas de Ana Mae Barbosa.

Aquela que teve o maior número de entradas é uma das que considerei acima como tendo ficado na fronteira entre os dois grupos de autores. No entanto, levando-se em consideração o modo como o artigo tem sido trabalhado pelos pesquisadores, apropriando-se da noção de experiência como um expediente crítico e bastante aproximado com a arte - inclusive, com iniciativas de seu autor em fazer essa vinculação -, tratei de agrupá-lo em nosso campo. Foi possível, assim, destacar 7 produtos (entre artigos e livros) como aqueles que tiveram mais frequência: são 75 entradas dedicadas a esse conjunto, dando uma breve ideia de quais materiais que têm tido maior aceitação dentro do coletivo do GT.

Em particular, vale destacar que os produtos com maior número de entradas, considerando-se a nacionalidade dos autores, colocam-nos diante de três autoras brasileiras de significativa expressão não apenas como intelectuais, mas como militantes pela construção de nosso campo de trabalho: Ana Mae Barbosa, Ivone Richter e Marly Meira. Cada uma e todas são responsáveis por importantes conquistas na esfera do ensino de arte, tanto à frente de entidades associativas (AGA, FAEB e INSEA - International Society for Education through Art, em especial) quanto em termos de produção, formação e difusão de conhecimento específico dentro do espectro da educação e arte.

\section{É POSSÍVEL CONCLUIR?}

Minha conclusão é simplesmente uma suspensão provisória do exercício reflexivo que comecei, e não um ponto de chegada. Retomando a intenção inicial, o exercício realizado teve por objetivo oferecer um panorama resultante de um exercício muito particular de leitura dos dados produzidos a partir do inventário dos 165 trabalhos aprovados pelo GT no intervalo já apresentado.

Os achados podem ser tomados como traços, rastros ou indícios que se prestam para diferentes análises, a depender da posição e das escolhas feitas por 
aquele que analisa. No meu caso, fui atrás de identificar as modas do GT: quais as temáticas mais frequentes e quais os autores e as obras mais frequentes nas referências daqueles trabalhos. Minha intenção era conhecer, ainda que eu tivesse hipóteses construídas a partir de minha assiduidade às reuniões, quais as ferramentas que o GT vem construindo e utilizando para exercer a crítica, para fomentar a criação, para possibilitar experiências — no sentido já destacado.

Somos um campo que historicamente tem sido alvo de ataques, em especial por parte daqueles que aderem ao conservadorismo e às práticas fascistas no cotidiano. Temos sido historicamente atacados por aqueles que não suportam a diferença, a heterogeneidade, a diversidade, a invenção, a singularidade. E, a despeito dos golpes que sofremos, temos sabido nos defender com perseverança e valentia, apoiados em ideias consistentes, fortes e rigorosas - muitas vezes, colocando em risco nossa própria existência, literal e metaforicamente falando.

Com que armas temos nos defendido? Com que ferramentas temos cavado túneis e trincheiras? Com que dispositivos temos revidado os ataques que sofremos? São as nossas ideias e as nossas experiências que se convertem nesse aparato de resistência e crítica. Educação e arte têm sido nossas armas, nossa munição, nosso alimento, nossas ferramentas, nossos instrumentos, nossas linguagens.

Mas não sou capaz de encerrar o assunto sem reiterar a necessidade da suspeita, de suspeitarmos de nós mesmos: até que ponto essas escolhas que temos feito respondem a exercícios de crítica e experiências de transformação? Acaso não fomos, um dia, nós mesmos, colonizados por essas ideias que hoje consideramos quase genuinamente nossas? Acaso não estamos capturados por uma rede que, imperceptível, nos faz crer que são nossas as ideias que nos foram infiltradas? Ainda acreditamos no que dizemos acreditar?

A exigência da suspeita pode nos levar à análise dessas nossas convicções. Desde quando acreditamos no que acreditamos? A que ideia renunciamos quando passamos a pensar como hoje pensamos? Até quando estamos dispostos a suportar o preço da posição que construímos?

Não se trata, simplesmente, de cada um fazer esse exercício. Trata-se de fazê-lo de forma individual, mas, igualmente, de forma coletiva: que ideias e convicções temos contribuído para disseminar, enquanto grupo? E sobre que ideias e convicções nos constituímos, como coletivo? Que demandas nos mobilizam, que tarefas nos arrebatam, que desafios nos conquistam? Que fronteiras arriscamos a ceder, e que outras defendemos com a nossa própria vida?

Minha provocação vem no sentido de reafirmar a crença em que outro mundo é possível, mas sem perder de vista que os habitantes desse outro mundo, esse que estamos ajudando a construir (e que podemos ser nós mesmos, junto com uns tantos que ainda não nasceram ou se juntaram a nós), também deverão acreditar que outro mundo será possível e lutar por isso: um outro desse outro que estamos construindo, e assim por diante. Nossos mundos são provisórios, são passagens, são tempos e espaços que não cessam de se transformar. Como a história, como a arte, como a vida. 


\section{REFERÊNCIAS}

ALMEIDA, C. M. C. A produção científica apresentada no GT Educação e Arte da ANPEd. In: REUNIÃO ANUAL DA ANPED, 34., 2011. Trabalho Encomendado pelo GT24. ANPEd, 2011. (mimeo.).

BARBOSA, A. M. Arte-Educação no Brasil: realidade hoje e expectativas futuras. Estudos Avançados, v. 3, n. 7, p. 170-182, 1989. https://doi.org/10.1590/S010340141989000300010

BARCELLONA, P. E1 individualismo propietario. Madri: Trotta, 1996.

BRASIL. Artes. Documento de Área. Brasília: DAV/Capes, 2009.

BRASIL. Relatório de Avaliação 2007-2009: Trienal 2010. Brasília: DAV/CAPES, 2010. Disponível em: http://trienal.capes.gov.br/wp-content/uploads/2011/03/ EDUCA\%C3\%87\%C3\%83O-REL-AVAL.pdf. Acesso em: 12 jul. 2019.

BRASIL. Ministério da Educação. Instituto Nacional de Estudos e Pesquisas Educacionais Anísio Teixeira (INEP). Sinopses Estatísticas da Educação SuperiorGraduação. Brasil, 2019. Disponível em: http://portal.inep.gov.br/web/guest/sinopsesestatisticas-da-educacao-superior. Acesso em: 29 set. 2019.

BUNCHAFT, G.; KELLNER, S. R. O. Estatística sem mistérios. Petrópolis: Vozes, 1997. v. 1.

DEWEY,J. Democracia e educação. 3. ed. São Paulo: Companhia Editora Nacional, 1959. DUVE, T. Cinco reflexões sobre o julgamento estético. Porto Arte, Porto Alegre, v. 16, n. 27, 2009. https://doi.org/10.22456/2179-8001.18187

FOUCAULT, M. O que é a crítica? [Crítica e Aufklärung]. In: BRITTO, F. L. (org.). Crítica e modernidade em Foucault: uma tradução de Qu'est-ce que la critique? [Critique et Aufklärung], de Michel Foucault. Dissertação (Mestrado em Filosofia) - Programa de Pós-Graduação em Filosofia, Universidade Estadual do Rio de Janeiro, Rio de Janeiro, 2005. p. 73-104.

FOUCAULT, M. Entrevista de Michel Foucault ao Le Nouvel Observateur. In: FOUCAULT, M. (org.). O enigma da revolta: entrevistas inéditas sobre a Revolução Iraniana. São Paulo: n-1 Edições, 2018. p. 16-36.

GOODMAN, N. Quando há arte? In: D'OREY,C. (org.). O que é a arte? A perspectiva analítica. Lisboa: Dinalivro, 2007. p. 119-133.

KANT, I. Resposta à pergunta: que é "esclarecimento" [“aufklärung”]? In: KANT, I. Textos seletos. 2. ed. Petrópolis: Vozes, 1985. p. 100-117.

LOPONTE, L. Educação e arte na ANPEd: a conquista de um novo espaço. In: CONGRESSO DA FEDERAÇÃODEARTE EDUCADORES DO BRASIL,17.,2007. Anais [...]. Florianópolis: Udesc, 2007. Disponível em: https://docplayer.com.br/62017710Educacao-e-arte-na-anped-a-conquista-de-um-novo-espaco.html. Acesso em: 12 jul. 2019. MACEDO, E.; SOUSA, C. P. A pesquisa em educação no Brasil. Revista Brasileira de Educação, v. 15, n. 43, p. 166-202, jan./abr. 2010. Disponível em: http://www.scielo. br/pdf/rbedu/v15n43/a12v15n43.pdf. Acesso em: 12 jul.2019. https://doi.org/10.1590/ S1413-24782010000100012 
PEREIRA, M. V. O limiar da experiência estética: contribuições para pensar um percurso de subjetivação. Pro-Posições, v. 23, n. 1 (67), p. 183-195, 2012. Disponível em: https://www.scielo.br/pdf/pp/v23n1/12.pdf. Acesso em: 12 jul. 2019. https://doi. org/10.1590/S0103-73072012000100012

\section{SOBRE O AUTOR}

Marcos Villela Pereira é doutor em educação pela Pontifícia Universidade Católica de São Paulo (PUC-SP). Professor da Pontifícia Universidade Católica do Rio Grande do Sul (PUC-RS).

E-mail: marcos.villela.pereira@gmail.com

Conflitos de interesse: $\mathrm{O}$ autor declara que não possuir nenhum interesse comercial ou associativo que represente conflito de interesses em relação ao manuscrito.

Financiamento: $\mathrm{O}$ estudo não recebeu financiamento.

Recebido em 12 de dezembro de 2019

Aprovado em 2 de outubro de 2020 